\title{
Primary nasal tuberculosis: Case report
}

\section{Nalan Alev Canbolat ${ }^{1}$, Erkan Tezcan ${ }^{2}$, Serdar Yanık $^{3}$, Ayse Neslin Akkoca ${ }^{4, *}$, Zeynep Tugba Ozdemir ${ }^{5}$, Aysegul Kaynar ${ }^{3}$, Ebru Tastekin ${ }^{6}$}

${ }^{1}$ İskenderun State Hospital,Department of Otorhinolaryngology, Hatay, Turkey

${ }^{2}$ Can State Hospital, Department of Otorhinolaryngology, Canakkale, Turkey

${ }^{3}$ İskenderun State Hospital, Department of Pathology, Hatay, Turkey

${ }^{4}$ İskenderun State Hospital ,Department of Family Medicine, Hatay, Turkey

${ }^{5}$ Bozok University Faculty of Medicine,Department of İnternal Medicine, Yozgat, Turkey

${ }^{6}$ Trakya University Faculty of Medicine,Department of Pathology, Edirne, Turkey

\section{Email address:}

ayseneslinoguzhan@hotmail.com (A. N. Akkoca)

\section{To cite this article:}

Nalan Alev Canbolat, Erkan Tezcan, Serdar Yanık, Ayse Neslin Akkoca, Zeynep Tugba Ozdemir, Aysegül Kaynar, Ebru Tastekin. Primary Nasal Tuberculosis: Case Report. American Journal of Health Research. Vol. 2, No. 5, 2014, pp. 316-318.

doi: 10.11648/j.ajhr.20140205.25

\begin{abstract}
Tuberculosis (TB) is an infectious disease that can exist in all organs and tissues. Although pulmonary TB is a more common form, extrapulmonary tuberculosis ( EPT) is still a major clinical problem. A fifty-four years old female patient attended with a complaint of a wound causing crusting and occasionally bleeding for 5 months, with no response to the use of antibiotics. Otorhinolaryngological examination including anterior rhinoscopy revealed a $1 \times 1.5 \mathrm{~cm}$ hypertrophic, irregular mucosal lesion on the left side of caudal septum. Excisional biopsy was performed. Pathological examination was reported as granulomatous inflammation. Pulmonary TB was not detected in chest clinic consultation. As a result of the clinical and histopathological evaluation the patient was diagnosed with primary nasal TB and anti-tuberculosis treatment was performed. As a result, primary nasal TB is a rare clinical entity but should always be kept in mind in the differential diagnosis.
\end{abstract}

Keywords: Nasal, Tuberculosis (TB), Extrapulmonary Tuberculosis (EPT)

\section{Introduction}

Tuberculosis (TB), is an infectious disease that may involve all organs and tissues. Pulmonary TB is more common, although the form of extrapulmonary tuberculosis (EPT) is an important clinical problem. TB bacilli can spread to other organs by lymphatic hematogenous pathways during primary infection. The latent bacili can reactivate at any stage of life when host (patient) resistance drops or organisms virulence increases and as a result EPT comes out (1). Nasal TB is rare and mostly holds the vestibule, cartilage of and anterior of inferior turbinate (2). If TB is suspected, diagnosis is the most important step. EPT, should be kept in mind in the differential diagnosis of infectious diseases of undetermined etiology. This article presented a female patient with a diagnosis of primary nasal TB who unanswered antibiotic treatment for a long time and diagnosed by biopsy.

\section{Case Report}

Fifty-four years old female patient was admitted to otorhinolaryngological clinic with complaints of sometimes nose bleeding causing wound and crusting. The patient's stated that there is a wound on her nose for five-months and unreformed complaints despite the use of antibiotics. There was no family history of tuberculous disease. Also no history of contact with TB patients. No history of long term drug use or any immunosuppressive therapy. She had no history of cigarette use and diabetes. In the clinic no complaints about respiratory system or weight loss. There was $1 \times 1.5 \mathrm{~cm}$ mucosal lesion with hemorrhagic incrustation, hypertrophic, irregular edges located in the far left side of caudal septum at the anterior rhinoscopy examination. Other systemic examination was natural.

Excisional biopsy was performed from the lesion. Pathological examination confirmed the presence of 
granulomatous inflammation. Complete blood count, biochemistry, erythrocyte sedimentation rate, HIV, Hepatitis, VDRL, chest radiography, computed tomography, AFB (acid-fast bacilli) search on sputum ,sputum culture, urinalysis, bacili on urine, urine culture examinations were performed, but pathological findings were not detected. Pulmonary tuberculosis was not detected in chest diseases consultation.

Nasal septum biopsy specimen was painted with EZN (Ehrlich-Ziehl-Neelsen).EZN painted positive bacilli were seen. (Figure 1). According to clinical and histopathological evaluations the patient was diagnosed as primary nasal TB and anti-tuberculosis treatment was started.

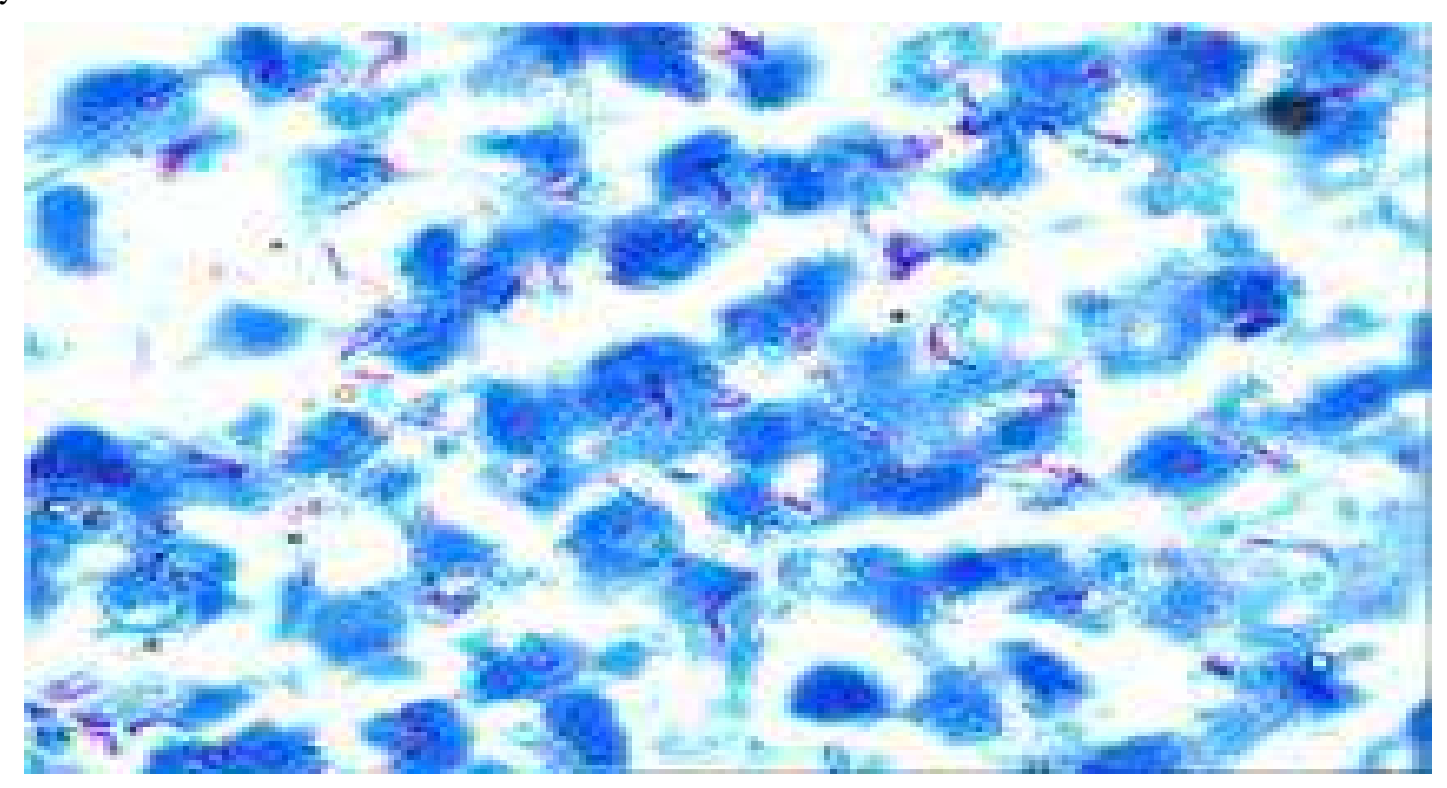

Figure 1. EZN stained positive bacilli in the nasal septum biopsy specimen.

\section{Discussion}

Tuberculosis is remarked as very rare on nasal and paranasal sinuses in the literature(3). Usually develops secondary to pulmonary TB with direct contact, hematogenous or lymphogenic ways(4). Nasal TB most common seen in immunocompromised patients or living in crowded and dirty conditions (5). Trauma and atrophic changes make easy the adhesion of bacilli to mucosa $(3,6)$. However, our patient had no history of immunodeficiency, trauma or pulmonary TB.

In cases of nasal TB common symptoms are epistaxis, nasal crusting, nasal congestion, runny nose and recurrent polyps $(6,7)$. In our case; nasal crusting, and epistaxis were present. Nasal tuberculosis can be seen as painful ,ulcerative, isolated lesion which holds the nasal septum and also can cause septal perforations when the disease progresses. Keeping the nasal vestibule and the external nose may cause nasal deformity too $(7,8)$.

There was only $1 \times 1.5 \mathrm{~cm}$ mucosal lesion with hemorrhagic incrustation, hypertrophic, irregular edges located in the far left side of caudal septum at the anterior rhinoscopy examinationand no other lesion was found. Difficulties in the diagnosis of EPT are; due to the small number of bacteria; generally lack of sufficient material for positive bacterial culture and difficulties in obtaining tissue biopsy from certain areas of the body for samples for acid fast bacilli (9).

The main diagnostic problem is that TB mimics other granulomatous diseases and malignancy. Tissue biopsies plays an important role in nasal TB (10). Histological examination caseating granuloma, Langerhans-type giant cells are seen. Non-caseating granulomas rarely can be observed (11). In our case, biopsy was reported as granulomatous inflammation. In the biopsy tissue presence of acid fast bacilli can be found by EZN staining. In studies more than $50 \%$ of the patients positive results were reported with this method $(12,13)$.

Cultures should be taken in cases of suspected nasal TB. Culture is the gold standard in the diagnosis of TB, but due to the difficulties in bacterial growth and slow reproductive rate ; positive culture is obtained in a minority of cases (14). In our case, there has been no growth in the culture. Today, for more rapid and accurate diagnose molecular diagnostic methods are used. Polymerase chain reaction (PCR) method species the identification of mycobacteria in a short time of 48 hours, while can also show the antibiotic resistance associated with mutation. PCR has sensitivity and specificity as $84 \%$ and $100 \%$ respectively $(15,16)$. In the differential diagnosis; Wegener's granulomatosis, Leprosy, Berillozis, sarcoidosis, fungal granulomas, Rhinoscleroma and syphilis should be considered $(10,17)$.

Surgery is not necessary when the disease is localized in nose and the standard anti-tuberculosis therapy is usually sufficient to treat the disease. However, drug resistance is always to be considered (18). Local complications such as scarring in the nose may require surgery when developed. The nasal lavage and removal of nasal crusts are important 
in local treatment. The treatment is short-lived in EPT cases for 6 and 9 weeks of treatment (19). Standart antituberculosis treatment was started in our case.

As a result, primary nasal $\mathrm{TB}$ is a rare clinical entity. Otorhinolaryngological specialists should always keep in mind nasal tuberculosis in the differential diagnosis. Suspected cases, microbiological and histopathological examination should be done.

\section{References}

[1] Centers for Disease Control and Prevention. Reported Tuberculosis in the United States, 2006. Atlanta, US: Department of Health and Human Services, CDC; 2007

[2] Braun-Falco O, Plewing G, Wolff HH, Winkelmann RK. Dermatology. 3rd ed. Berlin: Pringer-Verlag, 1984: 137.

[3] Ramakant D, Lokendra D. Primary Nasal Tuberculosis. Lung India 2008:25:102-3.

[4] Butt AA. Nasal tuberculosis in the 20th century. Am J MedSci.

[5] Halim, A. A.,Chooi, L. L., Hussin, S., \& Singh, A. (2013). Primary nasal tuberculosis and review of literature. Rawal Medical Journal, 38(4), 453-454.

[6] Aksoy F, Yildirim Y S, Taskin U, Bayraktar G, Karaaslan O. Primary nasal tuberculosis: a casereport. TuberkToraks 2010;58:297-300.

[7] Blanco Aparicio M, Verea-Hernando H, PomboF: Tuberculosis of the nasal fossa manifested by a polypoid mass. J Otolaryngol 1995;24:317-8.

[8] Choi YC, Park YS, Jeon EJ, Song SH: The disappeared disease: Tuberculosis of the nasal septum. Rhinology 2000;38:90-102.

[9] Subash C, Hamidah H, Naseem S, Mohamma A, Farheen A, Ismat L, et al. Extrapulmonary Tuberculosis: A retrospective review of 194 cases at a tertiary care hospital in Karachi, Pakistan. J Pak Med Assoc 2010;60:105-9.

[10] Ting YL, Po JL, Lai PC. Primary nasal tuberculosis presenting with septal perforation. J Formos Med Assoc 2007;106:953-5.

[11] Hup AK, Haitjema T, de Kuijper G: Primary nasal tuberculosis. Rhinology 2001;39:47-48.

[12] Ho JS, Young SP, Dong WS, Se JJ, Kee DC, Sang SL, et al. Diagnosis of mediastinal tuberculosis by using EUS-guided needle sampling in a geographicregion with an intermediate tuberculosis burden. Gastrointest Endosc 2010;71:1307-13.

[13] Eshete A, Zeyinudin A, Ali S, Abera S, Mohammad M.M. tuberculosis in Lymph Node Biopsy Paraffin- Embedded Sections. TubercResTreat 2011:127817. Epub 2011 Dec 13.

[14] Pamukcu Uyan A, Baysoy G. [Different clinical form of tuberculosis in childhood: three cases]. TuberkToraks. 2008;56(3):329-36.

[15] Kapur V, Li L-L, Hamrick MR, Plikaytis BB,Shinnick TM, Telenti A, Jacobs WR, BanerjeeA, Cole S, Yuen KY, Clarridge JE III, KreiswirthBN, Musser JM: Rapid Mycobacterium species as signment and unambiguous identification of mutations associated with antimicrobial resistance in Mycobacterium tuberculosis by automated DNA sequencing. Arch Pathol LabMed 1995;119:131-138.

[16] MoradNa: Tuberculous cervical lymphadenopathy: should antituberculous therapy be preceded by histological proof? Trop Doc 2000; 30: 18-20.

[17] Harries AD, Dye C. Tuberculosis. Ann Trop Med Parasitol. 2006 Jul-Sep;100(5-6):415-431.

[18] Nalini B, Vinayak S. Tuberculosis in ear, nose, and throat practice: its presentation and diagnosis. Am J Otolaryngol. 2006 Jan-Feb;27(1):39-45.

[19] Kim YM, Kim AY, Park YH, Kim DH, Rha KS. Eight cases of nasal tuberculosis.Otolaryngol Head Neck Surg. 2007 Sep;137(3):500-504 